\author{
И. М. Кобозева \\ Московский государственный университет имени М. В. Ломоносова \\ (Москва, Россия) \\ kobozeva@list.ru
}

\title{
КАЛЕЙДОСКОП СОСТАВНЫХ СОЮЗОВ НЕПОСРЕДСТВЕННОГО ПРЕДШЕСТВОВАНИЯ В РУССКОМ ЯЗЫКЕ: ПОКА НЕ ПРИЗНАННЫЕ, НО УЖЕ ФУНКЦИОНИРУЮЩИЕ СОЮЗЫ
}

В статье рассматривается один из механизмов образования русских составных союзов непосредственного предшествования, обеспечивающих наличие большого количества показателей связи с одним и тем же значением, одни из которых со временем устаревают и уступают место другим, - механизм грамматикализации темпоральных наречий со значениями 'сразу' или 'скоро', приводящий к их включению в качестве морфологических элементов в состав этих союзов. К синонимической группе союзов непосредственного предшествования относят: 1) союзные частицы только, лишь, едва, чуть; 2) составные союзы, представленные разнообразными сочетаниями указанных частиц (лишь только, едва лишь, едва лишь только и др.), а также устойчивыми сочетаниями только с союзами как и что - как только и только что; 3) двухместные союзы, представленные комбинацией вышеуказанных союзных частиц или составных союзов в придаточной части либо с «коррелятом» так или $m o$, либо с союзом как, $u$ или $a$ в главной части. В статье приводятся синтаксические, просодические и семантические аргументы в пользу того, что в данную группу в современном русском языке должны быть включены также союзы с грамматикализованными наречиями: сразу как (только), тотчас как (только). Обращается внимание на то, что составные союзы непосредственного предшествования с грамматикализованным темпоральным наречием уже существовали в русском языке (см. устаревший союз как скоро). Отмечается, что наречия со значениями 'сразу' и 'скоро' входят в состав союзов непосредственного предшествования и в других языках, что в конечном счете объясняется тождеством условий истинности сложноподчиненных предложений с союзами непосредственного предшествования и сложносочиненных предложений со значением 'P, и сразу / скоро (т. е. с нулевым / малым интервалом после P) Q'.

Ключевые слова: русский язык, союзы непосредственного предшествования, образование составных союзов, темпоральные наречия, грамматикализация, сразукак. 


\section{1. Введение}

В русском языке есть группа синонимичных подчинительных временных союзов, которые маркируют тот факт, что ситуация, обозначенная придаточной частью, непосредственно предшествует той, что обозначена главной частью. В типологии выражаемое ими темпоральное отношение рассматривается в рамках грамматической категории таксиса и называется «контактным предшествованием» [Храковский 2009, 11-113]. В [Русская грамматика 1980] они называются союзами со значением «непосредственного следования», что нарушает общий принцип номинации типов подчинительных союзов, состоящий в том, что название типа союза отражает семантическое отношение придаточной части к главной (ср. причинные, целевые, уступительные, временные и др. союзы), а не наоборот. В предложениях с союзами рассматриваемой группы придаточная часть находится к главной части в отношении предшествования, а не следования. В соответствии с этим принципом мы и называем союзы данной группы союзами со значением «непосредственного предшествования» (далее - союзами НП), как это принято также в Русской корпусной грамматике [Апресян, Пекелис 2012].

К данной группе в [Русская грамматика 1980] отнесены: 1) союзные частицы только, лишь, едва, чуть; 2) составные союзы, представленные разнообразными сочетаниями указанных частиц (лишь только, едва лишь, едва лишь только и др.), а также устойчивые сочетания только с союзами как и что - как только и только что; 3) двухместные союзы, представленные комбинацией вышеуказанных союзных частиц или составных союзов в придаточной части либо с «коррелятом» так или то либо с союзом как, $u$ или $a$ в главной части.

Эксплицируем общее для союзов данной группы значение на примере доминанты этого синонимического ряда - союза как только, самого частотного члена группы.

(1) Как только $P$, (так) $Q$ (для случая, когда $\mathrm{P}$ и $\mathrm{Q}$ - конкретные единичные события в прошлом $)=$

1) 'в $t_{i}\left(t_{i}<t_{j}\right)$ имело место событие $P$ '

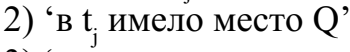

3) 'величина интервала I между $t_{i}$ и $t_{j}$ минимальна'

4) 'Q более существенно, чем P'

Компоненты значения 1-3 относятся к пропозициональному содержанию предложения, а компонент 4 отражает различия в коммуникативных (дискурсивных) статусах / рангах главной и придаточной частей: $\mathrm{P}$ - фон, Q - фигура [Talmy 1978], или P — сателлит, Q - ядро [Mann, Thompson 1987].

В главной части СПП с союзами НП факультативно употребляются темпоральные наречия сразу, тотчас, сейчас жее и под., которые согласно [Русская

${ }^{1}$ Иначе говоря, величина I столь мала (в масштабах ситуаций Р и Q), что ею можно пренебречь. 
грамматика 1980, § 2984] относятся к функциональной категории «конкретизаторов» - языковых выражений, позволяющих специфицировать интерпретацию союзов «недифференцированного значения». Все такие наречия относятся к семантической группе «адвербиалов типа ПОСЛЕ» [Богуславский 1996], т. е. таких наречных выражений, которые маркируют ситуацию Q, обозначаемую предложением, в котором они употреблены, как наступившую (или долженствующую наступить) после ситуации Р, введенной в ближайшем контексте или ясной из ситуации общения. В отличие от других наречий этой группы (затем, потом, вскоре и др.) данные наречия дополнительно указывают на «нулевой», или минимальный интервал между Р и Q. В ССП с союзом $u$, например, такие адвербиалы в составе присоединяемого конъюнкта, действительно, конкретизируют семантическое отношение между конъюнктами как отношение временного следования, а точнее непосредственного следования Q за $\mathrm{P}$ :

(2) $\quad P$, и сразу $Q$ (для случая, когда $\mathrm{P}$ и $\mathrm{Q}$ - конкретные единичные события в прошлом)

1) 'в $t_{i}$ имело место событие $P$ '

2) 'в $t_{j}\left(t_{j}>t_{i}\right)$ имело место $Q$ '

3) 'величина интервала I между $t_{i}$ и $_{\mathrm{j}}$ минимальна'

4) 'Р и Q одинаково существенны'

Как мы видим, семантическое представление (СемП) предложения (2) отличается от Семп предложения (1) только в коммуникативном аспекте: в (2) P и Q имеют одинаковый коммуникативный (или дискурсивный) статус. При этом компоненты, формирующие пропозициональное содержание (1) и (2) либо совпадают, либо логически эквивалентны. Действительно, $\mathrm{P}$ предшествует Q тогда и только тогда, когда Q следует за Р.

Ясно, что в СемП предложений типа (3):

Как только $P$, так сразу $Q$

дублирующие друг друга пропозициональные компоненты, вносимые союзом НП и наречием сразу (или синонимичным ему адвербиалом), конечно, не повторяются, но их повторное выражение в поверхностной структуре создает коммуникативный эффект подчеркивания, подобный тому, который наблюдается и в случаях редупликации некоторых союзов НП, ср. только-только $P$, (как) $Q$; едва-едва $P$, (как) $Q$. И в том, и в другом случае подчеркивается минимальность интервала между предшествующим событием Р и следующим за ним Q.

Таким образом, в составе предложений типа (3), содержащих союз НП и наречие сразу или любой другой синонимичный ему адвербиал, этот адвербиал в силу его избыточночти почти полностью десемантизируется. Можно предположить, что именно десемантизация темпоральных наречий со значением 'сразу’ создает базу для их дальнейшей грамматикализации, которая, как мы покажем далее, приводит к превращению некоторых из них в элементы составных союзов НП. 


\section{2. Союзы НП, производные от темпоральных наречий сразу и тотчас.}

Обращение к НКРЯ позволяет увидеть, что в [Русская грамматика 1980] при всем желании авторов дать полную картину языковых средств, выражающих семантические отношения между предложениями в составе СПП, не замеченными остались составные союзы, которые образованы на основе темпоральных наречий сразу и тотчас. Они не вошли в список синонимов союза как только, приведенный § 2984.

Анализ корпусных данных показывает, что в ряд союзов НП в современном русском языке вошел союз сразу как. Поиск по НКРЯ на дату обращения 04.12.2018 выдал десятки примеров, подобных нижеследующим²:

(4) Сам он посетил Чехова за день до отъезда того за гранииу, сразу как приехал в Москву. [Руслан Киреев. Чехов. Посещение Бога // «Нева», 2004]

(5) Вечером, т.е. сразу как приехали, позвали Лифиицев чай пить с пирогами ... [Нина Катерли. «Сквозь сумрак бытия» // «Звезда», 2002]

(6) Давид Якобашвили говорит, что о музее начал думать сразу, как стал собирать коллекиию...[Ирина Осипова. Новые русские музеи // «Эксперт», 2014]

(7) Мы учимся погружением и сдаем сразу, как освоили предмет. [коллективный. Форум: 227 школа (2013)]

(8) $\quad$ Уменя пудель воет сразу как я за порог... [коллективный. Форум: Ошейник АНТИЛАЙ ПОМОГАЕТ ЛИ ОШЕЙНИК (2011-2013)]

(9) - Я прислала тебе ее сразу, как ты пришла. [Полина Волошина, Евгений Кульков. Маруся (2009)]

Предложения (4) - (9) показывают, что пунктуационно союз сразу как оформляется пока по-разному. При постпозиции придаточного чаще между сразу и как мы видим запятую, но при этом сразу просодически не отделяется от как. Если в предложениях этого типа и есть просодический шов, то он проходит перед сразу, а не после этого первого элемента союза, точно так же, как это происходит в случае прочих составных коннекторов - как только, едва лишь, только лишь, едва лишь только, едва-едва и др. Такое расхождение не удивительно. Несоответствие между пунктуацией и просодией - не редкое явление в русском языке, см. (Кобозева, Захаров 2014).

Широко представлен в корпусе и трехэлементный составной союз сразу, как только (191 пример на указанную выше дату):

${ }^{2}$ Мы не можем назвать точное число релевантных примеров из 739 выданных вхождений по запросу биграммы «сразу на расстоянии 1 от как», потому что среди них попадаются предложения с другой семантико-синтаксической структурой, напр., Мишину отпустили сразу, как и всех вызванных женщин.... К тому же в выдачу по такому запросу попадают и примеры с союзом сразу как только. Тут требуется статистический анализ, подобный тому, который был проведен в отношении освященных авторитетом академической грамматики союзов НП в [Киданова 2017]. 
(10) Сразу, как только я приехала, мы устроили репетицию. [Татьяна Тарасова, Виталий Мелик-Карамов. Красавица и чудовище (1984-2001)]

(11) Тумаш уснул сразу, как только свалился наземь... [Василь Быков. Болото (2001)]

(12) Замуж она быстро высккочила. Сразу, как только кончила учиться на учительнииу английского языкка. [Петр Акимов. Плата за страх (2000)]

(13) ... Они позвонят? - Сразу, как только. - Ну что ж... [Виктор Пронин. Банда 8 (2005)]

(14) Мыр работаем без сна почти 20 часов - и это только в пещере, а ведь мы начали спуск не сразу, как только проснулись. [Константин Серафимов. Экспедиция во мрак (1978-1996)]

(15) Пушкин пишет пародию на Шекспира ..., сразу как только сам стал нашим Шекспиром. С. Г. Бочаров. О возможном сюжете: «Евгений Онегин» (1999)]

В письменном тексте, за исключением единичных, примеров типа $(15)^{3}$, cpaзу и как только разделены запятой. При этом, если придаточное в препозиции, то просодического шва между сразу и как только нет, элементы союза следуют один за другим без пауз, аналогично элементам союза едва лишь только. Сразу в (10) вместе с как только, несомненно, образуют союз, синтаксически и семантически относящийся к придаточной части, а не к главной части, в которую, если ориентироваться на пунктуацию, якобы вложено придаточное, начинающееся с как только. В этом легко убедиться, если попробовать устранить из (10) составляющую, возглавляемую как только. Оставшаяся цепочка (Сразу мы устроили репетицию) имеет неестественный для русского языка порядок слов, поскольку в предложениях с ненулевым подлежащим наречия с семантикой непосредственного следования, к которым относится сразу, занимают позицию после группы подлежащего (Мьз сразу устроили репетиичю)).

Что касается СПП типа (11) с сочетанием сразу, как только на границе между главной и придаточной частью, то в них данное сочетание может произноситься как с паузой между сразу и как только, так и без паузы. Но, с паузой или без нее, было бы странно рассматривать сразу как «конкретизатор» значения союза как только. Не случайно в «Русской грамматике» все типы адвербиальных «конкретизаторов» при союзах НП иллюстрируется примерами, в которых адвербиал находится в постпозитивной главной части, см. (Ук. соч., § 2984).

Ярким свидетельством того, что элемент сразу в сочетании сразу, как только синтаксически относится к придаточной части (образует с ней одну составляющую), а не к главной части, служит отделимость конструкции сразу, как только $P$. Как известно, отделимость - один из синтаксических критериев фразовой категории [Тестелец 2001, 134-135]. В данном случае это категория союзной группы, или (придаточной) клаузы. Отделимость представлена в форме парцелляции в (12),

3 Заметим, что данный пример взят из текста, написанного филологом, и можно думать, что в данном случае пунктуационное оформлении более точно отражает коммуникативный замысел автора. 
и в форме фрагментирования в (13). Слово сразу в рамках парцеллированной или фрагментированной части уже не совпадает по значению с наречием сразу, указывающим на то, что ситуация, обозначенная предикатом клаузы, с «нулевым» интервалом следует за некоторой другой ситуацией, введенной в рассмотрение ранее, поскольку предикат парцеллированной или фрагментированной вместе со сразу клаузы (который в (13) был опущен) обозначает ситуацию, которая предшествует введенной ранее. Это означает, что наречие сразу грамматикализовалось, став элементом союзов НП сразу (,) как и сразу (,) как только.

Впрочем, процесс грамматикализации еще не вполне завершился. Об том свидетельствует возможность модифицировать наречный элемент союза при помощи наречия почти, как в (16) или частицы же, как в (17):

(16) Кирик, он из командировок без подарков никогда не возвращался и камешки начал мне дарить очень давно, почти сразу как поженились. [Марина 3осимкина. Ты проснешься. Книга первая (2015)]

(17) Она вскочила сразу же, как скрылся Прат... [Юлия Лавряшина. Улитка в тарелке (2011)]

Еще одним семантическим доказательством принадлежности сразу придаточной клаузе служит сфера действия отрицания в предложениях типа (14). Если бы сразу было наречием в функции обстоятельства времени в составе главной части, то придаточное с союзом как только, следующее за этим наречием, должно было бы пониматься как уточняющее обстоятельство времени. В такой конструкции показатель отрицания при первом обстоятельстве включает в свою сферу действия (СД) только его, но не второе обстоятельство. Так, в предложении Mы пробыли в пещере не долго, до обеда, обстоятельство до обеда не входит в СД отрицания. То есть, компонент смысла 'Мы пробыли в пещере до обеда' не отрицается. Аналогично в (14) не должен был бы отрицаться компонент смысла, соответствующий обстоятельственному придаточному как только проснулись - 'интервал между $\mathrm{t}_{\mathrm{i}}$, когда (мы) проснулись, и $\mathrm{t}_{\mathrm{j}}$ (когда мы начали спуск) был минимальный'. Но единственно возможная интерпретация (14) - та, в которой отрицается именно этот компонент смысла: 'интервал между $\mathrm{t}_{\mathrm{i}}$, когда мы проснулись, и t (когда мы начали спуск) НЕ был минимальным’ (т.е. к 20 часам беспрерывной работы в пещере надо добавить еще какое-то время, проведенное без сна). Гипотетическая интерпретация, в которой отрицание включало бы в свою СД сразу, но не включало как только $(P)$ должна была бы выглядеть так: 'мы начали спуск в $\mathrm{t}_{\mathrm{k}}$ после некоторой ранее упомянутой ситуации $\mathrm{X}$, имевшей место в $t_{i}$; интервал между $t_{i}$ и $t_{k}$ HЕ был минимальным; мы проснулись в $t_{j}$; интервал между $\mathrm{t}_{\mathrm{j}}$ и $\mathrm{t}_{\mathrm{k}}$ был минимальным'. Такая интерпретация соответствовала бы, например, следующему сценарию: мы могли бы начать спуск в пещеру сразу по прибытии на место, но решили лечь поспать и начали спуск, как только проснулись. Но такая интерпретация совершенно не вписывается в контекст (14). Таким образом, сразу, как только попадает в сферу действия отрицания как одно целое - составной союз НП. 
Союзы сразу как и сразу как только (теперь мы имеем основания записывать их без противоречащей синтаксическому и семантическому членению СПП запятой перед как) по данным основного корпуса НКРЯ более частотны, чем такие удостоенные упоминания в [Русская грамматика 1980] союзы «непосредственного следования», как едва лишь, чуть только, лишь, только-только, едва-едва, только лишь, только чуть, чуть лишь (см. данные о частотности последних, полученные в корпусном исследовании [Киданова 2017]).

Очевидно, что составные союзы с элементом сразу занимают место их устаревающих синонимов тотчас как и тотчас как только, также обойденных вниманием в «Русской грамматике». Вот лишь несколько примеров из НКРЯ с составными союзами с элементом тотчас:

(18) На карточке его была приписана просьба быть к нему непременно, тотчас как возвращусь. [Роман Шмараков. Камеристка кисти Клотара // «Сибирские огни», 2013]

(19) Лариса, тотчас как только осталась одна с Подозеровым, взяла его за руку ... [Н.С. Лесков. На ножах (1870)]

По внутренней форме пары союзов с элементом сразу и с элементом тотчас аналогичны: тотчас - книжный синоним сразу в современном русском языке. В НКРЯ союзы НП, производные от наречия тотчас встречаются значительно реже, чем их синонимы, производные от сразу: всего 41 вхождение тотчас как только против 191 вхождения сразу как только. При этом большая часть примеров с союзом тотчас как (только) (примерно две трети) относится к XVIII-XIX векам, а среди тех, которые относятся к XX веку, отсутствуют примеры из разговорной речи или интернет-коммуникации.

\section{3. Устаревшие союзы НП, производные от темпоральных наречий.}

Единственный союз НП с элементом наречного происхождения в его составе, упомянутый в «Русской грамматике» в набранном петитом примечании, - это устаревший союз как скоро, снабженный соответствующей стилистической пометой (устар.).

В НКРЯ мы обнаружили два союза НП, производные от наречия скоро - как скоро и тотчас как скоро, в настоящее время вышедшие из употребления. Союз как скоро представлен в НКРЯ шестью примерами, из которых последний по времени относится к 1928 году:

(20) ... больные, присланные в дом умалишенных заблаговременно, т. е. как скоро обнаружились первые признаки их сумасшествия, нередко, выздоравливают совершенно. [Ю.В. Каннабих. История психиатрии (1928)]

Союз тотчас как скоро представлен восемью примерами, относящимися к XVIII-XIX векам, последний из которых по времени принадлежит перу Льва Толстого: 
(21) Соблазны власти... представляются достойной изелью деятельности людей только до тех пор, пока она не достигнута, но тотчас, как скоро человек достигает их, обличают свою пустоту и теряют понемногу свою притягательную силу...[Л.Н. Толстой. Царство Божие внутри вас, или христианство не как мистическое учение, а как новое жизнепонимание (1893)]

Еще один вышедший из употребления «деадвербиальный» союз НП - это только что. Трактовка его в [Русской грамматике 1980] как непосредственно произведенного от частицы только, представляется нам ошибочной. Союз НП только что в деривационном аспекте отличается от всех прочих составных союзов с элементом только. Если в образовании последних непосредственно участвует семантический дериват ограничительно-выделительной частицы только, то союз только что связан с этой частицей опосредованно, а непосредственно он образован от темпорального адвербиала только что. В режиме дискурса этот адвербиал обозначает момент времени, непосредственно предшествующий моменту речи, а в режиме нарратива - моменту в прошлом, заданному в ближайшем контексте (ср. Пойдем пообедаем. - Я только что пообедал и Меня пригласили к столу. Я только что пообедал, и потому отказался от угощения). Очевидно, что данный адвербиал служит маркером таксиса контактного (= непосредственного) предшествования. В синтаксической позиции союза, связывающего две клаузы, такой адвербиал приобретает союзную функцию, практически не меняя своего таксисного значения.

В основном корпусе НКРЯ зафиксировано всего два примера, оба относящиеся к XIX в., один из которых одноместный, а второй - двухместный, см. (22):

(22) P.S. Только что собрался бросить в ящик предыдущче два листика, как получил Ваше дорогое письмо. [П. И. Чайковский. Письма Н.Ф. фон-Мекк (1882)]

Место данного союза в грамматике современного русского языка должно быть там же, где находится союз как скоро - в примечаниях ${ }^{4}$.

\section{4. Отдельные параллели в других языках}

Отметить, что составные союзы НП, образованные от наречий со значением ‘сразу' и 'скоро', встречаются и в других языках.

Так, во французском языке существует союз НП aussitôt que, букв. 'сразу что' Это точная параллель русскому сразу как, если учесть, что элемент quе восходит к единственному во французском языке изъяснительному союзу (комплементатору) que, а в русском языке действуют два комплементатора - что и как, выбираемые в зависимости от логического типа придаточной клаузы: что - тип «факт / пропозиция», как- тип «событие» [Арутюнова 1988, Падучева 1986]. В [Кобозева

${ }^{4}$ Причиной попадания только что в список «действующих», не устаревших временных союзов, вероятно, был авторитет А.М. Пешковского, который в своем знаменитом труде именно на примере СП только что он вошел, (как) началась музыка разъяснял трудности разграничения сочинения и подчинения в случае, когда компоненты того, что мы называем двухкомпонентным коннектором, оказываются в разных предложениях в составе СП (Пешковский 1935, 413-414). 
2019] на этой основе объясняется, почему в составе временных союзов в русском языке может фигурировать элемент как, но нет ни одного временного союза с элементом что. Таким образом, элемент как в составе союза НП сразу как безальтернативен.

В английском языке существует союз НП as soon as, букв. 'как скоро как'. Это почти точная параллель устаревшему русскому как скоро, если не считать дублирования as. Напомним, что в группе русских союзов НП встречаются союзы, образованные путем редупликация союзных частиц: едва-едва, только-только. Но трехэлементных союзов с двумя совпадающими элементами не встречается. Даже если речь идет о двухместных союзах, элемент, находящийся в главной части, не может совпадать ни с одним из элементов составного союза, находящегося в придаточной части. В [Русской грамматике 1980] это формулируется в виде правила, запрещающего использовать элемент как в главной части, если в придаточной употребляется союз как только. Возможно, однако, что этот запрет продиктован не собственно языковыми ограничениями, а чисто стилистическими соображениями. Ср. нарушающий данный запрет пример СПП из романа всеми признанного русского писателя:

(22) ...как только вы явитесь в кальсонах в милицию и скажете, что виделись с человеком, лично знавшим Понтия Пилата, - как моментально вас привезут сюда, и вы снова окажетесь в этой же самой комнате. [М. А. Булгаков. Мастер и Маргарита, часть 1 (1929-1940)]

Возможно, это стилистические погрешность, не замеченная редактором, возможно - опечатка, но ощущения грамматической неправильности в любом случае не возникает.

В связи с указанными параллелями возникает вопрос: в случае составных союзов с наречными элементами имеем ли мы дело с влиянием французского или английского языков на русский, или же это независимые проявления сходства путей семантической деривации? Однако это тема для отдельного диахронического сопоставительного исследования. Отметим лишь, что в отличие от русских «деадвербиальных» коннекторов, их французские и английские аналоги в письменной форме не имеют запятой между исходно наречным и исходно союзным элементами коннектора.

\section{Литература}

Апресян В. Ю., Пекелис О. Е. Подчинительные союзы // Русская корпусная грамматика [Электронный ресурс] URL: http://rusgram.ru/, 2012.

Арутюнова Н. Д. Типы языковых значений: Оценка. Событие. Факт. М.: Наука, $1988.341 \mathrm{c.}$

Богуславский И.М. Сфера действия лексических единиц. М.: Школа «Языки русской культуры», 1996. 464 с.

Киданова M.E. Корпусное исследование структуры составных коннекторов, выражающих отношение контактного предшествования // Вестник Моск. ун-та. Серия 9. Филология. 2017. № 4. 
Кобозева И.М. Семантика и дистрибуция союзов что и как в функции комплементаторов // Русская грамматика: Структурная организация языка и процессы языкового функционирования. Москва: URSS, 2019. С. 33-42.

Кобозева И.М., Захаров Л.М. Просодия как ключ к пониманию смысла и ее искажение в «кривом зеркале» пунктуации // Филология и культура. Philology and culture. 2014. №2 (36). С. 27-32.

Падучева E. В. О референции языковых выражений с непредметным значением» // Научно-техническая информация. Сер. 2. 1986. № 1. С. 23-31.

Русская грамматика. Т. 2. Синтаксис / гл. ред. Н. Ю. Шведова. М.: Наука, 1980. $709 \mathrm{c}$.

Тестелеи Я.Г. Введение в общий синтаксис. М. : Изд-во РГГУ, 2001. 798 с.

Храковский В. С. Таксис: семантика, синтаксис, типология // Типология таксисных конструкций / отв. ред. В. С. Храковский. М. : Знак, 2009. С. 11-113.

Mann W., Thomson S.A. Rhetorical Structure Theory: A Theory of Text Organization. University of Southern California, 1987.

Talmy L. Figure and Ground in Complex Sentences. // Universals of human language. Vol. 4. Syntax / ed. by J. Greenberg. Stanford, CA: Stanford University Press,1978. P. 625-649.

\author{
Irina M. Kobozeva \\ Lomonosov Moscow State University \\ (Moscow, Russia) \\ kobozeva@list.ru
}

\title{
THE KALEIDOSCOPE OF COMPOUND CONJUNCTIONS OF IMMEDIATE ANTERIORITY IN RUSSIAN: AS YET UNRECOGNIZED BUT ALREADY FUNCTIONING CONJUNCTIONS
}

The article is focused on one of the mechanisms of forming compound conjunctions of immediate anteriority in Russian. This mechanism is the grammaticalization of temporal adverbs with one of two meanings ('at once' or 'soon') that ultimately leads to their inclusion in the morphological structure of compound conjunctions. This and other mechanisms produce a lot of synonymous conjunctions, of which some eventually fall out of use, leaving others to take their place. The group of synonyms includes: 1) so called «conjunctive particles» tol'ko 'only', lish 'only', jedva 'barely', chut' 'a little bit'; 2) compound conjunctions, representing various combinations of the given particles (lish tol'ko, jedva lish, jedva lish tol'ko, and others), and also stable combinations of tol'ko with the conjunctions kak 'as' and chto 'that' (kak tol'ko and tol'ko chto); and 3) «two-part compound» conjunctions, consisting of a given «conjunctive particle» or «compound conjunction» in the subordinate clause and «correlative» (tak or to), or conjunction ( $k a k$ 'as', $i$ 'and' or $a$ 'and / but') in the main clause. We give syntactic, prosodic, and semantic 
arguments advocating for the inclusion of compound conjunctions containing the grammaticalized adverbs srazu 'at once' (srazu kak, srazu kak tol'ko) and totchas 'at once' (tot chas kak, totchas kak tol'ko) in the group. We note that the conjunctions of immediate anteriority formed through the grammaticalization of temporal adverbs already existed in Russian previously (cf. the obsolete conjunction kak skoro, lit. 'as soon', mentioned in academic grammars). We also note that adverbs with the meaning 'at once' or 'soon' are incorporated into the structure of conjunctions of immediate anteriority in other languages, as well. This fact can be explained by the identity of truth conditions of complex sentences with conjunctions of immediate anteriority and corresponding compound sentences with adverbs denoting a minimal or small time interval between the two events denoted by the conjuncts.

Keywords: conjunctions of immediate anteriority, Russian, compound conjunction formation, temporal adverbs, grammaticalization.

\section{References}

Apresyan V. Yu., Pekelis O.E. [Subordinating conjunctions]. Russkaya korpusnaya grammatika [Russian corpus grammar]. Available at: http://rusgram.ru (accessed 23.06.2019) (in Russ.)

Arutyunova N. D. Tipy yazykovykh znachenii: Otsenka. Sobytie. Fakt [Types of linguistic meanings: Evaluation. Event. Fact]. Moscow, «Nauka» Publ., 1988. 341 p. (in Russ.)

Boguslavskii I. M. Sfera deistviya leksicheskikh edinits [The scope of lexical items]. Moscow, Shkola «Yazyki russkoi kul'tury» Publ., 1996. 464 p. (in Russ.)

Khrakovskii V.S. [Taxis: semantics, syntax, tipology] Tipologiya taksisnykh konstruktsii [Typology of taxis constructions] ed. V.S. Khrakovskii. Moscow, «Znak» Publ., 2009, pp. 11-113. (in Russ.)

Kidanova M.E. [Corpus study of the structure of compound connectors expressing the relation of immediate anteriority] Vestnik Moskovskogo universiteta. Ser. 9. Filologiya, 2017, no. 6, pp. 209-221. (In Russ.)

Kobozeva I.M. [Semantics and distribution of the conjunctions chto 'that' and kak 'as' in their complementizer function] Russkaya grammatika: Strukturnaya organizatsiya yazyka i protsessy yazykovogo funktsionirovaniya [Russian grammar: structural organization of the language and the processes of language functioning]. Moskva, «URSS» Publ., 2019, pp. 33-42. (in Russ.)

Kobozeva I. M., Zakharov L. M. [Prosody as a key to the utterance meaning and its distortion in the «false mirror» of puctuation] // Filologiya i kul'tura. Philology and culture, 2014, no. 2 (36), pp. 27-32. (in Russ.)

Mann W., Thomson S. A. Rhetorical Structure Theory: A Theory of Text Organization. University of Southern California, 1987.

Paducheva E. V. [On the reference of linguistic expressions that do not denote objects]. Nauchno-tekhnicheskaya informatsiya. Ser. 2, 1986, no 1, pp. 23-31. (in Russ.) 
Russkaya grammatika, T. 2 Sintaksis [Russian grammar, Vol. 2 Syntax] ed. N. Yu. Shvedova. Moscow, «Nauka» Publ., 1980. 709 p. (in Russ.)

Talmy L. Figure and Ground in Complex Sentences. Universals of human language. Vol. 4. Syntax / ed. by J. Greenberg. Stanford, CA: Stanford University Press, 1978, pp. 625-649.

Testelets Ya. G. Vvedenie v obshchii sintaksis [Introduction to general syntax]. Moscow, RGGU Publ., 2001. 798 s. (in Russ.) 